\title{
Balance teológico de la UPOLI Al final del siglo y milenio
}

\section{Resumen}

El presente trabajo parte de un libro que se realizara en la UPOLI, en ocasión de su 40 aniversario de fundación (2007). Dada su plena vigencia, tenemos el honor de publicarlo en nuestra revista Cultura de Paz, como parte del acompañamiento que el IMLK viene brindando desde nuestras páginas en el año del 50 aniversario (1967-2017). El Rev. José Miguel Torres h., teólogo ecuménico, pastor bautista y pacifista (q.e.p.d), nos ofrece una lectura teológica de la fundación y desarrollo de la UPOLI, el imaginario de quienes escribieron su propia historia, los factores que incidieron en la riqueza de su visión: bíblicos, políticos, sociológicos, históricos y ecuménicos. El teólogo ecuménico deja abiertas las puertas de las nuevas generaciones a continuar enriqueciendo con nuevas perspectivas teológicas esta historia también abierta y de anticipación que representa la UPOLI.

Palabras clave: Ecumenismo, bautista, visión, evangelio, reconciliación.

\section{Abstract}

- This paper was published in a book in the occasion of the 40th : anniversary of foundation of UPOLI (2007). Given its full validity, - we have the honor to publish it in our Culture of Peace journal, as part of the accompaniment that the IMLK has been providing from our pages in the year of the 5oth anniversary (1967-2017). The Rev. José Miguel Torres, ecumenical theologian, Baptist and pacifist pastor (R.I.P), gives us a theological reading of the foundation and development of UPOLI, the imagination of those who wrote their own history, factors that influenced wealth of his vision: biblical, political, sociological, historical and ecumenical. The ecumenical

: theologian leaves the doors open to new generations to continue : enriching this history with new theological perspectives, also open and anticipated history that UPOLI represents.

Key words: Ecumenism, Baptist, vision, gospel, reconciliation.
En el marco de la planeación estratégica de la UPOLI a que fue convocado el liderazgo de la Universidad por las autoridades superiores, en una continuación de los primeros pasos de planeación estratégica que tuvo la UPOLI, a partir del año 1991 y que determinó el primer Plan Estratégico de Desarrollo Institucional para el periodo 1999-2003, con énfasis en el área académica, se tuvo en mente el propósito de revisar, validar, o redefinir y reorientar el quehacer de la Universidad para determinar el mejor rumbo a seguir en los escenarios posibles o necesarios del futuro de corto y mediano plazo, tarea ésta

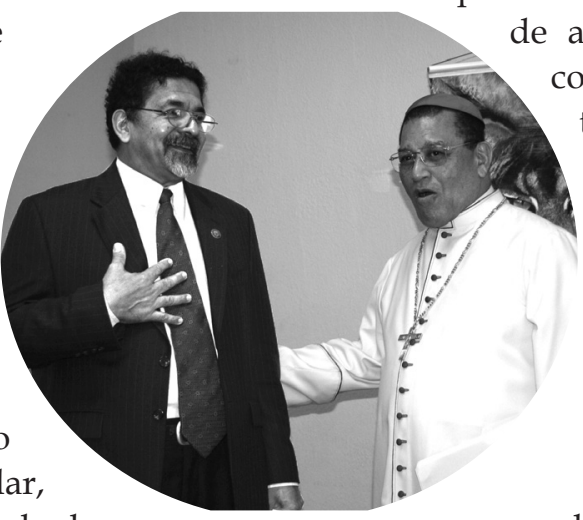

que a su vez conllevó el compromiso colectivo de análisis participativo dinámico, global, continuo y flexible, que posibilitará la toma de decisiones y la formulación de estrategias en pro de los objetivos $\mathrm{y}$ metas universitarias generales $\mathrm{y}$ específicas, en respuesta al entorno cercano y lejano que se tiene, y a ese macro y micro ambiente desde la naturaleza y ser upoliano interno.

Teniendo presente entonces ese paso de avanzada en materia de planificación Rev. José Miguel Torres h. y Su Eminencia Reverendísima Cardenal Miguel Obando y Bravo. de la UPOLI, una distinción más en su largo trajinar, se consideró válido y necesario en la coyuntura de fin de siglo y milenio y a pocos

1 Pacifista, Pastor Bautista, Teólogo Ecuménico (q.e.p.d). 
años de cumplir la UPOLI cuatro décadas de fundación, aportar como insumos fundamentales, algunos ingredientes histórico-axiológicos que conforman implícita o explícitamente, la visión y autoimagen de la UPOLI desde las vertientes y tradiciones de la herencia bautista-cristianaevangélica y ecuménica que precedió y sustentó la razón de ser de la UPOLI, que permita un balance teológico de esta Universidad al final del milenio.

\section{Los modelos universitarios de referencia y la UPOLI}

El Dr. Carlos Tünnermann Bernheim en su obra Orígenes de la Institución Universitaria (Siglo XII hasta la creación de la Universidad Imperial de Napoleón, 1808), señala que las universidades coloniales de Hispanoamérica se inspiraron en el modelo de la Universidad de Salamanca, y ésta a su vez, de la Universidad madre de Bolonia.

También hace notar cómo la reforma protestante contribuyó al nacimiento y desarrollo de las universidades que a su vez, le sirvieron de reducto intelectual, como la Universidad de Ginebra (1559), creada por el reformador Calvino; Marburgo (1527); Konigsberg (1543) y Jena (1558); Heidelberg y Halle (1649), esta última, la primera Universidad verdaderamente moderna.

A su vez en Francia, frente a la Universidad de París, regida originalmente por el Obispo y el canciller católico local y posteriormente bajo la conducción del Papa de Roma, se levantó la Universidad Protestante de Strasburgo que por su ubicación en la Alsacia recibía influencia de las dos vertientes universitarias, tanto la alemana como la francesa.

La Universidad Politécnica de Nicaragua paralela a las universidades de América Latina que recibieron a mediados del segundo milenio y siglo, la influencia de esas tradiciones y modelos de la Europa Septentrional y Meridional (Bolonia, Salamanca y Alcalá de Henares), también rescata su propia herencia y mucho de su especificidad, de las vertientes universitarias ecuménicas-protestantes que fueron espacios de la reforma en su lucha por la libertad de conciencia, de pensamiento y de libre examen, como las universidades alemanas de: Hamburgo, Königsberg y Berlín, la Universidad Protestante de Strasburgo, Francia, así también de las universidades de Ginebra, Suiza, Oxford y Cambridge en Inglaterra, de los Países Nórdicos y de los Estados Unidos, como la Universidad de Harvard (1636) fundada por los Congregacionales y la de Princeton fundada por los Presbiterianos.

Sustentando las anteriores afirmaciones no se puede obviar que los líderes fundadores de la UPOLI y entre ellos, el Dr. Norberto Herrera Z. y el Rev. y Dr. Rolando Gutiérrez Cortés, estuvieron relacionados a la World Christian Students Federation, organismo cristiano mundial universitario con más de 100 años de existencia, fundado a iniciativa de Harvard, Yale y Cambridge en el Castillo de Vadstena, 1895, Noruega, y con un trabajo en universidades en más de ciento veinte países. Además que se debe recordar que estos líderes fundadores, se vieron envueltos en experiencias académicas en universidades como Ginebra; Strasburgo; Berlín Prali y Tesalónica, Grecia, donde además de participar en programas de conducción ecuménica universitaria y perfeccionamiento teológico en esas centenarias universidades, tuvieron la oportunidad de participar en espacios académicos institucionales para aprender a forjar el testimonio cristiano en la formación del liderazgo profesional - técnico intelectual de la sociedad en su conjunto.

\section{Fundamento y misión de la UPOLI}

Al trabajar en la planeación estratégica de cualquier entidad $u$ organismo, resulta muy importante conocer su fundamento y Misión. Para el caso de la UPOLI esto le viene dado desde su matriz esencial, que es la "Gran Comisión" encomendada por el originador del Evangelio, Jesucristo, esencia de la proclamación del 
amor de Dios, por el hombre y el universo, y quien encomendó predicar el Evangelio y bautizar en el nombre de la Trinidad como expresión del paso a la nueva vida, del pecado a la gracia y como signo de restauración y del nuevo nacimiento, de la nueva criatura - base de toda redefinición dinámica o cambio, como fruto del arrepentimiento que es sobre todo, redimensión de prioridades y rumbos hacia su Reino. Además, la tarea de "enseñar todo lo que Él había instruido" y sus enseñanzas van desde la lucha por la verdad y las llaves de la ciencia, pasando por los valores del Sermón del Monte, hasta la inauguración del Reino de Dios.

Esta misión la UPOLI la ha sabido cumplir desde su nacimiento y fundación en un pesebre de pobreza y limitaciones, surgiendo como la segunda universidad evangélica de Centroamérica y aún parece, de América Latina, a lo largo de tiempos y coyunturas que muchas veces al decir el poeta "fueron color de noche invernal", como cuando se le entorpeció su labor académica, investigativa y de extensión cultural por medidas lesivas, atentatorias contra la integridad de la UPOLI.

Sin embargo, esta Universidad de motivación cristiana evangélica, persistió con sus velas desplazadas y su visión firme a puerto seguro. El crecimiento cuantitativo tuvo su lugar a la par de la calidad como señal de su buena salud. No fue nunca su afán hacer cosas extraordinarias (que si las sabe hacer) con la obsesión de la competencia para vanagloria o por jactancia humana. Se trató siempre que como comunidad de verdadero compañerismo cristiano, cumpliera las tareas normales, inconclusas y nuevas, en pro del desarrollo sostenido y de la complementariedad, y como dice la Escritura, para crecer en el amor unos a otros, y para con todos (as) (1era Tesal. 3:12) crecer en gracia y conocimiento (2da Pedro 3:18) en la Obra del Señor (1era. Corintios 15:58), crecer en responsabilidad social, política, ecológica, holística (Efesios 4:1:15).

La misión de la UPOLI a la luz de su naturaleza,

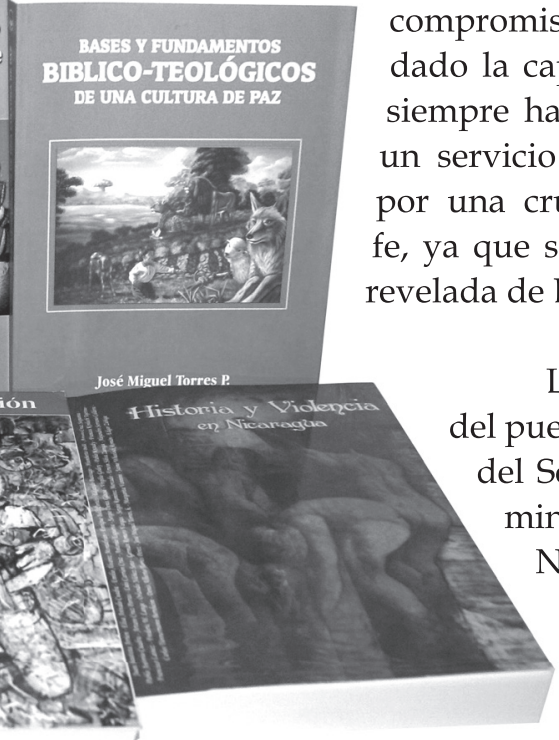

LaUPOLI es una expresión pueblo de Dios y de la Iglesia del Señor, con una vocación y ministerio muy particular en Nicaragua, que introdujo en la realidad social global de Nicaragua varias pautas y rumbos que otras universidades del país y deCentroamérica tendrán que transitar a corto y mediano plazo, como parte de sus responsabilidad en la construcción de pensamientos, valores y actitudes generacionales, como su Programa de Cultura de Paz que ha logrado el cultivo de mentalidades de reconciliación y solución de conflictos, auspiciando encuentros y acercamientos de posiciones ideológicas y políticas encontradas, para buscarle solución y salidas al inherente problema de la violencia de siglos en la historia del país, para lo cual la UPOLI ha tenido una vocación pionera, y ha afirmado este valor de paz (Shallom, Eirene), que le ha permitido una capacidad de respuesta a la crisis, en una cadena de coyunturas como una de sus grandes fortalezas.

A la vez, tales énfasis de la UPOLI han ayudado mucho a reducir la polarización política y a difundir una imagen civilizada del país a nivel internacional. La participación de las mujeres en el soporte, construcción, inspiración y consolidación de la UPOLI, tiene una vasta tradición desde sus comienzos, en términos de vidas consagradas, al servicio de Jesucristo, con entrega y dedicación sacrificial de lo más amado de sus vidas.

En el futuro, estudios más pormenorizados de las líneas gruesas de estos procesos vividos se profundizarán, en relación a cada una de las décadas y etapas pasadas de la UPOLI en sus respectivos contextos, evolución y desarrollo, y cómo se vivió cada etapa o sus coyunturas claves. La actuación de sus docentes. Su pensar o actuar teológico - político, su experiencia con Cristo en Dios en medio de los cambios, conscientes 


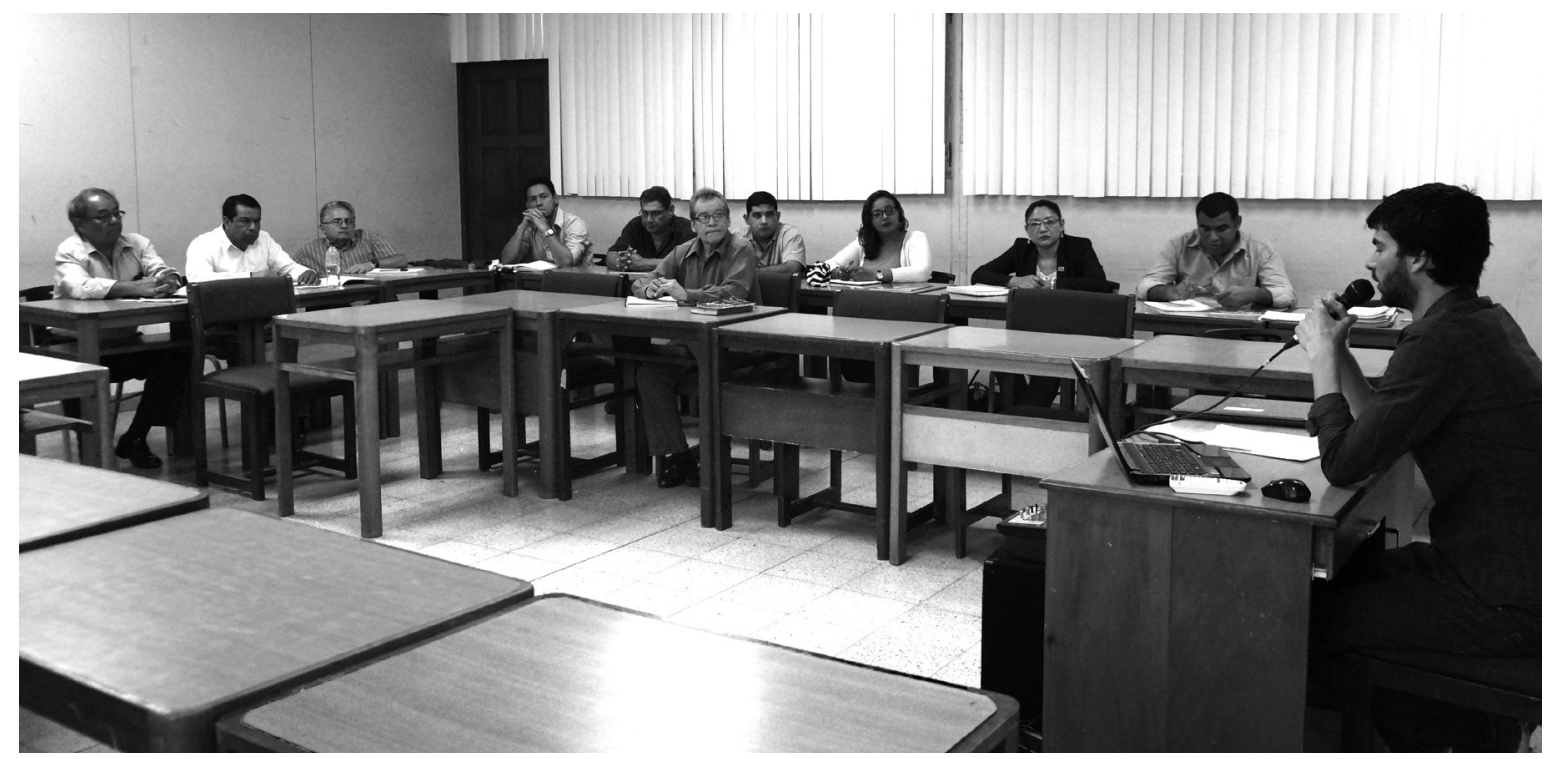

MSc. Pablo Ronchi, especialista en Estudios de Paz, Cooperación y Desarrollo de la Universidad Jaume I, facilitando el taller con el tema "Democracia y ciudadanía en América Latina", a docentes que imparten la asignatura Cultura de Paz de la UPOLI y la UNI. Foto: R. Públicas UPOLI.

que hay nuevas riquezas de vertientes a rescatar como memoria histórica. Incluso, hay personas síntesis que simbolizan énfasis que van desde lo pedagógico metodológico hasta lo administrativo - financiero contable, desde la conducción política - estratégica hasta la formulación de un pensamiento ya identificado de la UPOLI, desde lo novedoso y efectivo de la medicina homeopática y el derecho laboral, hasta la economía, administración, banca y finanzas - mercadotecnia; desde los niveles de servicio de la enfermería, hasta la Maestría de Investigación Cualitativa o la Maestría en Desarrollo Rural, o bien desde la computación y sistemas, hasta las estadísticas; desde lo cultural - artístico y danza hasta lo adoracional litúrgico - teológico; desde las áreas básicas hasta los cursos de educación a distancia; desde los centros o institutos de investigación, hasta sus escuelas y las sedes regionales; desde las relaciones públicas hasta los procesos de divulgación.

Toda esta riqueza de realizaciones cotidianas de la UPOLI reflejan sobre todo relaciones de trabajo basadas en la confianza interpersonal, el acercamiento mutuo, el respeto y la autonomía de cada vocación, especialidad o ministerio, esto como constante (independiente de uno que otro exabrupto) que propician las propuestas múltiples, auténticas y propias del conglomerado que es la UPOLI, y reflejan su riqueza de dones y el estímulo a la creatividad.

\section{La visión en la Planificación Estratégica de la UPOLI}

Aunque el término visión, etimológicamente tiene que ver con el sentido de la vista, a su vez, es una percepción de todo ser, casi siempre ligada al futuro, mediada por la cultura en torno a las explicaciones globales limites y la producción de significados. En el mundo bíblico, la visión significa revelación como don, ligada a un "adventus" que trasciende el porvenir y que se puede vivir en anticipación y sirve como guianza del presente para leer los signos de los tiempos.

En la creatividad del Dios del Génesis, antes de la palabra creadora se presupone en Dios una visión del universo que soñó, diseñó y concibió, incluida la redención humana antes de ser creada y que ésta se revelase (Efesios 1:4).

En la vida de los patriarcas, Dios llama en Abraham a un pueblo para ser bendición de toda la Tierra y la visión de esto materializado, es una descendencia como las estrellas y la arena del mar. Posterior al diluvio, la visión del arcoíris es una promesa y garantía de la continuidad de la vida y el designio divino contra la destrucción. 
En el Éxodo, la visión de la Tierra Prometida da a conocer a un Dios liberador que sufre con las mayorías humanas en la historia.

En los profetas, los cielos nuevos y la tierra nueva (Isaías 65:17-25) es la visión de un mundo nuevo hacia el cual se camina para su realización plena.

En el Nuevo Testamento, en la encarnación del verbo eterno de Dios, Jesucristo, inaugura su Reino que puede salvar un mundo enfermo y cuyas señales mesiánicas se anticipan en el jubileo (Lucas 4:18).

En el Apocalipsis de Juan, la visión de la Ciudad Santa, cuyo artífice

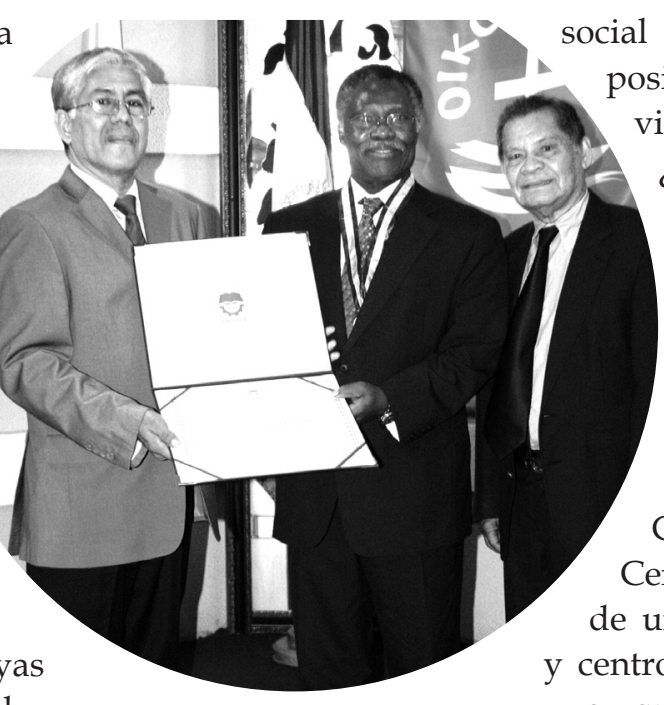

Ing. Emerson Pérez Sandoval, Rector de la UPOLI (2004-2013); Rev. Dr. Samuel Kobia, Secretario General del CMI y Lic. Hugo Silva, Presidente del Patronato de entonces. (q.e.p.d). Foto: R. Públicas UPOLI.

ocial global de las décadas, hicieron posible la creación de la UPOLI? ¿Cuál visión subyacía en su liderazgo? ¿Fue la UPOLI un movimiento o un evento pedagógico antes de ser una institución?

En la correspondencia del Rector Fundador, el Dr. Norberto Herrera, para la organización de la I Conferencia Cristiana Universitaria de Centroamérica, se conoce la selección de un equipo docente mundial, latino a quienes se les plantea temáticas $\mathrm{y}$ asuntos que reflejan la visión universitaria cristiana.

El Dr. Mauricio López, teólogo, sociólogo y filosofo, ex Rector de la es Dios y que desciende para morar con los hombres, es el "punto omega" de todas las luchas humanas. De estas grades visiones se generan otras visiones. Es la visión de la UPOLI, tenemos como pabellón sagrado estas visiones bíblicas-evangélicas que nos permiten superar desfases en el tiempo, que nos anticipan que la vida vencerá sobre la muerte, que al final el amor triunfará sobre el odio y el mal y, que la verdad iluminará sobre los engaños y errores, que la justicia romperá toda operación.

La UPOLI es una expresión de un compañerismo heredero de visiones fundantes que se debe preservar, porque sus visiones atravesaban sus trabajos, vivencias, sufrimientos y oraciones, $\mathrm{y}$ aun, sus enfermedades $\mathrm{y}$ muerte; tantas experiencias vitales de las que nosotros ya somos parte como continuidad, como testigos de la providencia del Dios que ayer les dio a ellos sentido y dirección y que hoy a nosotros también, nos conduce y nos invita a continuar plantando su cruz en medio de los tiempos presentes.

Si bien en la visión de los bautistas desde comienzos de siglo se incorporaba como estrategia de trabajo misionero la creación de instituciones (hospital, colegio, escuela de enfermería, seminario teológico), y se hablaba de una universidad bautista, fue hasta mediados de la década del 60 que se inició y cristalizó tal esfuerzo. ¿Qué antecedentes y condiciones, además del contexto Universidad Estatal de Mendoza, es invitado a venir siendo a la sazón Secretario Mundial de Iglesia y Sociedad del Consejo Mundial de Iglesias (CMI), Consejo que ese año se encontraba abocado al montaje de la Conferencia Mundial del Tercer Mundo, más grande después que la Intercontinental del Cairo, organizada por Nasser, Tito y Surkano. Con la diferencia de que a las conferencias del CMI iban hasta los Secretarios de Estados Americanos y la contraparte de los debates la hacían teólogos como J. Hromadka y M. Oposcensky, el primero "Premio Lenin de la Paz", en el campo socialista, lo cual habla del nivel de incidencia de tales eventos ecuménicos.

Mauricio ese año fue apermisado por cuatro días para salir de Ginebra y vino a Nicaragua a traer cuatro conferencias magistrales: "La revolución tecnológica", "La revolución social y política", "La condición humana de hoy" y "Los cristianos y la revolución técnica y social de nuestro tiempo".

Alexander John de la División de Misión y Evangelización del CMI, trabajaría sobre "El ecumenismo"; el Rev. Dr. Emilio Castro de UNELAN "La conversión, el señorío de Jesucristo, el servicio cristiano, la tenencia y propiedad en la Biblia"; Samuel Escobar "Evangelización en Universidad"; el Dr. Jorge Monterroso "La realidad indígena en Centroamérica, tenencia y propiedad de la tierra". 


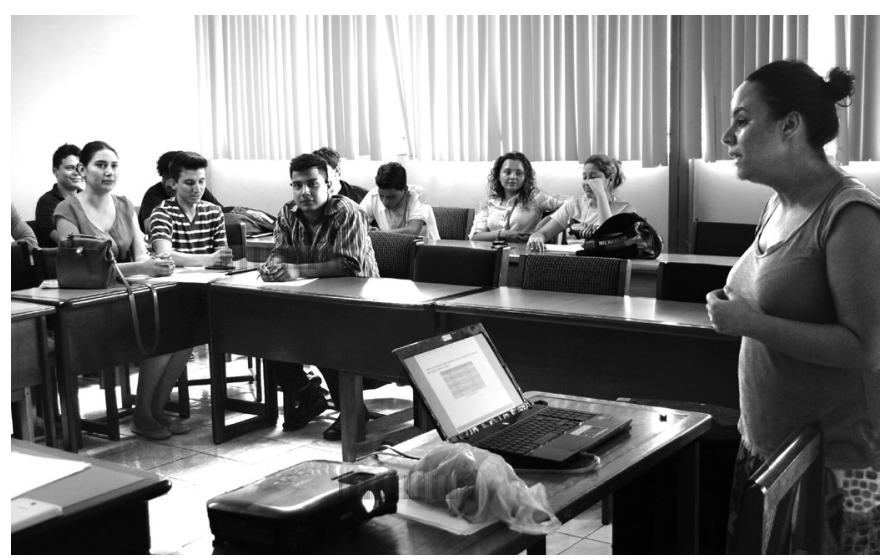

MSc. Esther Afonso, especialista en Estudios de Paz, Cooperación y Desarrollo de la Universidad Jaume I, facilitando el taller sobre transformación de conflictos a directiva de UNEN-UPOLI. Foto: R. Públicas UPOLI.

Los sub-temas solicitados por el Proto-Rector Herrera eran: Vietnam y otras situaciones explosivas con carácter de crisis mundial, las nuevas repúblicas africanas, el militarismo latinoamericano y el caso de la República Dominicana; el cristianismo y el existencialismo; vialidad posible entre el mundo occidental y oriental, América Latina, una tercera posición.

Estaban presentes también en la correspondencia y en la mente, la revolución cubana y el rol de los cristianos. La Mariano Gálvez como la primera Universidad Evangélica de América Latina en Guatemala, la reforma agraria ó colonización en Nicaragua, la misión de la universidad y la revolución en Latinoamérica. Este conjunto temático fue el marco de referencia y el universo mental - conceptual que estaba en el intelecto de aquella visión y que pudo canalizarse de distintas formas. Sin embargo, el designio divino conllevó a crear una matriz generadora, que fue la UPOLI.

Aquel evento ecuménico universitario lo inuguró el Dr. Carlos Tünnermann Bernheim, quien se estrenaba como Rector de la UNAN. Hubo un dialogo con el ideólogo marxista Fernando Gordillo y la poetisa quizás, más militante de izquierda en este tiempo, Michelle Najlis. Por la American Baptis Home Mision Society participaba el Dr. Aarón Webber. Había también un centenar de universitarios desde Guatemala a Panamá, profesionales laicos evangélicos de la región, todo ello fue el caldo y cultivo que conformaba el universo mental y visionario en que nació la UPOLI,

\section{En cuanto a la conducción de la UPOLI}

La UPOLI a finales del milenio contaba con un Rector y Patronato, cuyas vidas convertidas están enraizadas en Jesucristo y su Reino, que por ello trabajan con sentido de dirección y significado trascendente en la conducción de esta extraña "grey". Ellos saben por su naturaleza creyente, el valor de la palabra iluminadora de esperanza, urgencias, esfuerzos circunstancias, en búsqueda de solución, a veces faltas del oxigeno del evangelio.

Es evidente que Dios les llamó a servirle en medio de sus hermanos y hermanas y en el peregrinaje de 40 años, los fundadores y los relevos, todos ellos (as) han sido probados en una vasta práctica de entrega, servicio y compartir de lucha y sueños.

Saben compartir su liderazgo en pro de la consolidación del trabajo, involucrándose en las acciones necesarias para lograr la convergencia y unanimidad. Ellos orientan y llenan los alfolíes propios y de los demás con convicciones espirituales, apoyo y solidaridad en situaciones de sufrimiento, porque también han padecido humillaciones dolorosas, como las vividas con la pérdida del estatus y autonomía de la UPOLI durante diez años.

Un Rector con claridad de su rol como impulsor principal del proyecto universitario, probado por vocación de crítica universitaria, aun en contextos adversos, identificado con la causa fundamental de su pueblo, impulsando procesos docentes, despertando la fe en cuadros desechados que fueron piedras angulares en ocasiones, continuando la tarea de la transformación secular o espiritual integralmente, cultivando el compañerismo fraterno como crecimiento y madurez de las partes, promoviendo la reflexión de la misión universitaria, valorando constantemente lo que se está haciendo y recuperando los enfoques interdisciplinarios que logren integrar el saber tecnológico-profesional a lo ético-espiritual. Valorizando recursos cognoscitivos en el actual auge globalizante, contextualizando la visión estratégica de la UPOLI y su incidencia en la sociedad.

$\mathrm{Su}$ herencia bautista-ecuménica no ha sido en su relacionamiento una exigencia confesional. Supo colocarse a la cabeza del redescubrimiento del rol de la UPOLI en la década de los 80, en una época de cambios y transformaciones profundas, afrontando a la vez 


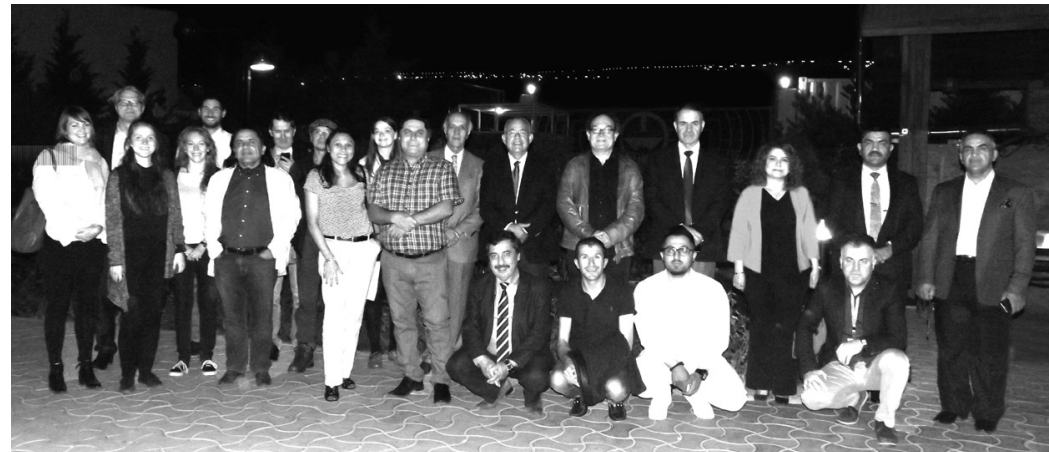

La MSc. Soren Chamorro, Responsable de Relaciones Internacionales y Proyectos del IMLKUPOLI, con Miembros de ICRoV, en la Universidad de Sulaymaniyah (región del Kurdistán iraquí), participando en la Conferencia Internacional Reconstrucción de sociedades en guerra: continuidad y nuevos inicios (octubre, 2016).

la reformulación de objetivos y administración de la crisis por la imposición de un estatus diferente de la UPOLI en momentos tensionantes que requerían valor y perseverancia en la fortaleza de Dios, para no claudicar y más bien luchar, motivando a los demás en la esperanza del triunfo inobjetable, en la recuperación del legítimo estatus.

Ha diseñado con el Patronato dentro de la auto-comprensión de la UPOLI, la reformulación de objetivos para los tiempos venideros, para incorporar a la formación profesional una más sólida concepción científica del mundo, fortaleciendo siempre el compromiso social desde lo académico-práctico, y desde su ejemplo personal de involucramiento en el escenario público para mérito institucional; orientando la sensibilidad cristiana, el enlace con los procesos de producción y las nuevas tendencias tecnológicas, el aporte concreto a la sociedad, fortaleciendo la formación de recursos docentes y de investigación, la capacitación del estudiante nuevo y el seguimiento al egresado, la promoción de la investigación científica, la planificación estratégica, la organización, dirección y supervisión y el asesoramiento para el sistema productivo nacional.

\section{Valores-estilo y calidad de la vida de la UPOLI}

Esta visión reconocida- heredada, inspira e ilumina hasta hoy a nivel integral el proyecto educativo de la UPOLI, con los valores y principios que dan rostro, nombre y carácter propio.
El lema de la UPOLI "Sirviendo a la comunidad", fue una inspiración consecuente con las causas y orígenes, reflejo claro y evidente de la visión cristiana de esta institución. Servir, es el llamamiento de Jesucristo, el siervo sufriente por excelencia, quien renunció a su privilegio y se humanó hasta la muerte. El valor del servicio se practica en la cultura nicaragüense, a través de la hospitalidad que nos caracteriza. La UPOLI trasunta estas dos dimensiones y toma para sí, la acción de Jesucristo, quien asumió la culpa humana, la culpa de todos, por lo cual murió en lugar de todos (as). Allí está la base de toda solidaridad y acción de servicio, como capacidad de donarse en amor por los demás.

El concepto de comunidad, descansa en la afirmación bíblica sobre la realidad intra-trinitaria de Dios como fuente de toda comunión, corporatividad y colectividad, donde el valor que hace posible el amor y la reconciliación, son "dos o tres reunidos en su nombre", como garantía de su presencia y no el aislamiento egoístaindividualista. Pero más aún, esa naturaleza comunitaria de Dios es huella o imagen y semejanza que lleva la criatura humana llamada a desarrollar la imaginación creadora de instrumentos, utopías, tecnologías, ciencias y esperanzas, que descansan en la iniciativa de las promesas del Dios caracterizado por su fidelidad eterna.

Esta visión que impele y reconforta a la UPOLI, para seguir trabajando por la regeneración ética, social y espiritual de la nación y el mundo, desde la identidad de ser cuerpo de Jesucristo: encarnado, crucificado y resucitado y adveniente. Por ello, nuestras iniciativas de paz, la causa de la justicia y la meta de la reconciliación, frente a tanta degradación y mal, como motivación para trabajar por revertir el pecado, por generar procesos de redención. Es válido seguir trabajando por la salvación de la humanidad, del país, de la comunidad, y aunque Jesucristo resucitado haya parecido iluso al encarga esta tarea a aquellos que parecían inútiles y que eran la nada del mundo, el llamado y el compromiso es a seguir firmes y adelante, tomados de su mano, siendo llamados a ser la sal de esta tierra y la luz del mundo, para posibilitar nuevas motivaciones y esperanza. 